\title{
Influence of curvature change on soil arching effect in underground space development
}

\author{
Binbin $\mathrm{Xu}^{1,2,3,4^{*}}$ \\ ${ }^{1}$ Tianjin Port Engineering Institute Co. Ltd. of CCCC First Harbor Engineering Co. Ltd., Tianjin, 300222, China \\ ${ }^{2}$ CCCC First Harbor Engineering Co. Ltd., Tianjin, 300461, China
}

${ }^{3}$ Key Lab. of Geotechnical Engineering of Tianjin, Tianjin, 300222, China

${ }^{4}$ Key Lab. of Geotechnical Engineering, Ministry of Communication, Tianjin, 300222, China

\begin{abstract}
This paper mainly studies the behavior of axisymmetric radial interaction between soil and structure under radial stress. Considering the possible factors in the interaction, such as the soil arching effect caused by the finite curvature, a simplified model is established. The influence of curvature change on the stress field, strain field, displacement field and stress-strain relationship is analyzed. Finally, the status of various factors in the axisymmetric radial interaction and the influence of their changes on the interaction are proposed.
\end{abstract}

\section{Research background}

With the rapid development of economy and the rapid growth of population, urban land is more tense and traffic is more crowded. This forces the housing construction and road traffic to develop to the high altitude and underground, and the high-rise building has almost become the symbol of modern city. For example, Sears building in Chicago is $443 \mathrm{~m}$ in height, Kuala Lumpur twin tower building in Malaysia is $450 \mathrm{~m}$ in height, Shanghai Jinmao Building in China is $421 \mathrm{~m}$ in height, and Shanghai global finance building is $460 \mathrm{~m}$ in height. The appearance of these high-rise buildings undoubtedly puts forward more strict requirements for foundation treatment.

When human beings increase the height of ground buildings to increase living space, they also focus on the development of underground space. With the rapid development of modern underground engineering, there are many kinds of typical projects. All kinds of underground power stations are growing rapidly. Among them, the number of underground hydropower generation has exceeded 400 in the world, with a power generation capacity of more than 4.5 billion watts. The construction of underground power station is a huge underground project. Rogo hydropower station in the former Soviet Union has 5.1 million cubic meters of earthwork and 1.6 million cubic meters of concrete. 294 tunnels and chambers have been excavated, with a total length of 62 $\mathrm{km}$. A large number of underground storage rooms have been built all over the world, and their construction technology has been constantly innovated ${ }^{[1-3]}$. At present, the development and utilization of urban underground space has become an important part of urban construction.
Some developed countries have gradually integrated underground commercial streets, parking lots, underground railways and underground pipelines into a multi-functional underground complex.

The interaction between soil and structure is essentially the interaction between different media. It is an interdisciplinary research topic involving soil mechanics, structural mechanics, numerical simulation calculation and many other disciplines ${ }^{[4-6]}$. It involves many emerging research hotspots in the field of mechanics, such as boundary nonlinearity, interface problems and so on. At the same time, it is very important for energy, construction, water conservancy, municipal, military, electric power, etc As well as transportation and many other industrial sectors, it is also the key to project safety and quality. Based on the above importance of soil and structure in all aspects, it has been highly valued and widely studied by scholars and research institutions at home and abroad since ancient times.

\section{Contact surface treatment method}

Due to the great difference between the soil and the structure in the mechanical properties such as stiffness and strength, under certain force conditions, in addition to the transfer of force, there may be discontinuous deformation behaviors such as relative displacement, such as relative dislocation or cracking, between the soil and the structure, If the finite element method for continuum is directly used to solve the problem, there will be large errors, even serious distortion of the calculation results. For this kind of problem, at present, the soil and structure are usually regarded as a continuous whole, and different

\footnotetext{
*Corresponding author: 109930595@qq.com
} 
constitutive models are adopted for the soil or structure, while some treatments are carried out for the interface between the soil and structure.

a) Direct method: direct method is to transform contact problem into a constrained quadratic programming problem.

b) Contact mechanics method: the contact mechanics method is to treat the interface between soil and structure as a kind of boundary conditions, in which Lagrange multiplier method and penalty function method are most commonly used. The multiplier and penalty value in Lagrange multiplier method are equivalent to the contact stress or contact force on the interface, and this method can accurately meet the boundary conditions, However, the diagonal element of the stiffness matrix will be zero, resulting in no solution. Penalty function method overcomes the disadvantage of ill conditioned Lagrange multiplier method, but it can only approximately satisfy the contact boundary conditions. In order to overcome their shortcomings and make full use of their advantages, a modified Lagrange multiplier method was developed later. The common advantage of this kind of method is that it can directly obtain more real contact stress or contact force. The contact mechanics method is usually used to simulate the problems of rock joints and fissures. There are some limitations in the simulation of soil, so the application in this field is still relatively small.

c) Interface element method: the interface element method is introduced between soil and structure. It is a special finite element with very thin thickness or close to zero thickness, which plays a transitional role between soil and structure. This method is based on the preassumed constitutive relationship of interface, and adjusts the parameters in the element constitutive model by incremental and iterative means, The stress deformation relationship is approximately simulated. Because of its clear concept and easy operation, it is widely used in the field of geotechnical engineering.

Numerical simulation is a new way for human beings to understand the world. Since theoretical analysis and scientific experiments, numerical simulation has become the most important means for human beings to understand the world. It is mainly used to solve the following two kinds of problems: the problem that it is impossible to carry out experiments, and the problem that the cost of experiments is too high. At the same time, it integrates the characteristics of theoretical analysis and scientific experiment. Numerical simulation / simulation is no longer limited to scientific calculation, and is widely used in scientific research, engineering and production.

\section{Computational model}

\subsection{Model simplification}

Under the action of positive symmetrical load, the angle and horizontal displacement of the positive symmetric structure cannot occur. So only one quarter of the structure can be taken for analysis, as shown in Figure 1.

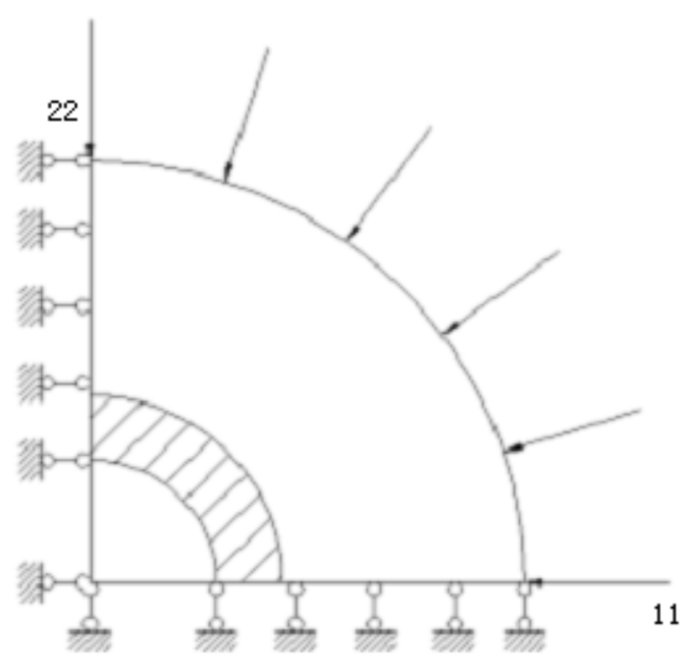

Figure 1. 1/4 model

\subsection{Influence of different curvature}

In the field of soil mechanics, soil arching is used to describe a phenomenon of stress transfer, which is realized by exerting the shear strength of soil. Terzaghi confirmed the existence of soil arching effect through movable door test ${ }^{[8]}$.

Terzaghi's definition of soil arching effect is: "when a part of the supporting soil yields, the yield soil will move out of its original position, and the relative movement of the yield soil and the adjacent static soil will be hindered by the shear stress between the two parts of the soil, because the shear stress resistance tends to keep the yield soil in its original position, The phenomenon that the earth pressure transfers from the yield region to the adjacent static region is usually called soil arching effect. Sometimes, when the yield soil moves more than the adjacent soil, the soil arching effect will also occur According to this definition, the soil arching effect includes two parts: the decrease of the earth pressure at the yield position and the increase of the earth pressure near the yield position.

But the conclusion is discussed under the condition of zero curvature. In this problem, under the action of axisymmetric static earth pressure of the surrounding soil, the curvature of the structure studied is finite, and there will be different performances. Different structural supports require different stresses when yield, and the external of the yield structure may produce soil arch effect. On the one hand, the yielding soil bears the confining pressure of the part, but the pressure is gradually reduced, which makes the stress in the yield soil decrease, on the other hand, the soil near the outer side of the yielding soil will bear some pressure due to the soil arch effect, And with the obvious soil arching effect increases gradually, and the arching effect is very obvious, because the supporting structure itself is an arch structure.

Consider selecting different model sizes to represent different curvatures, and reduce the size in turn according to the proportional relationship to obtain three groups of data, as shown in Table 1. 
Table1. Model size

\begin{tabular}{|c|c|c|c|}
\hline & $\mathbf{R 1}(\mathbf{m})$ & $\mathbf{R 2}(\mathbf{m})$ & $\mathbf{R 3}(\mathbf{m})$ \\
\hline NO.1 & 3 & 5 & 25 \\
\hline NO.2 & 2 & 3.2 & 25 \\
\hline NO.3 & 1 & 1.6 & 25 \\
\hline
\end{tabular}

\subsection{Influence of grid meshing}

In FEM, different grid technology will have a certain impact on the results. Generally speaking, the finer the grid, the more accurate the calculation results will be, but the longer the calculation time will be. At the same time, we can also improve the mesh density of a certain part according to the accuracy of the results, in order to get more accurate solutions.

In the study of soil structure interaction, the structure and the soil near the interface will be the focus of consideration. The thickness of the structure is relatively small relative to the soil, and the grid density can not be the same as that of the soil. Otherwise, the changes in many details will not be so obvious. Only the structural grid is subdivided, Only in this way can we deeply consider the variation law of unknown variables in the contact surface and inside the structure; The soil near the contact surface and the surrounding soil can not use the same grid division, the general rule should be from the inside to the outside, and the grid density of the soil gradually decreases.

\section{Result analysis}

Under the confining pressure of $5 \mathrm{MPa}$, the influence of different curvature is compared. At this time, each model has five different material compositions. If the results are obtained and all the analysis is carried out, at least five times should be carried out, but actually it is not necessary. The key problem is to make clear the purpose of the comparison in this step: only the influence of different curvature is considered, so the interference of other factors should be excluded. According to the above analysis, the comparison should choose between the two different model sizes with the least material influence.

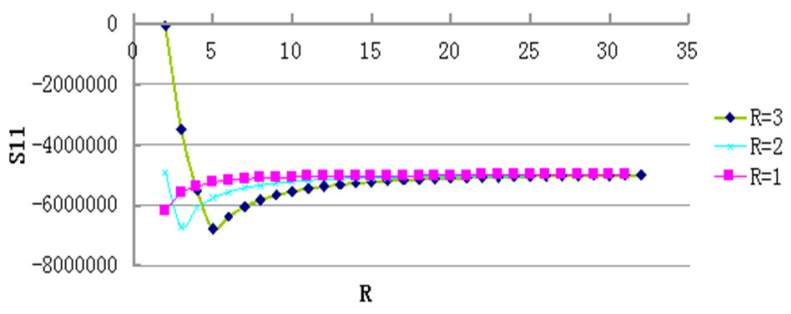

Figure 2. Comparison of S11 under different curvature

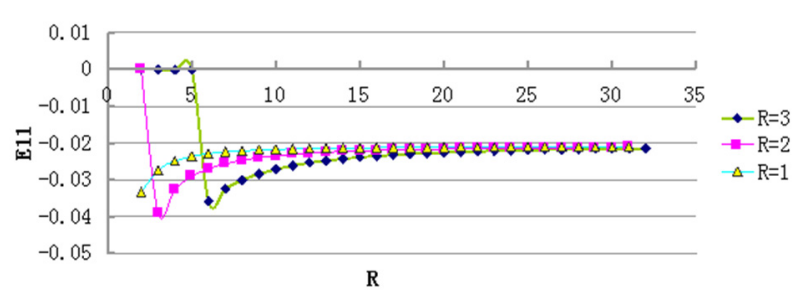

Figure 3. E11 ratio of elastic material with different curvature

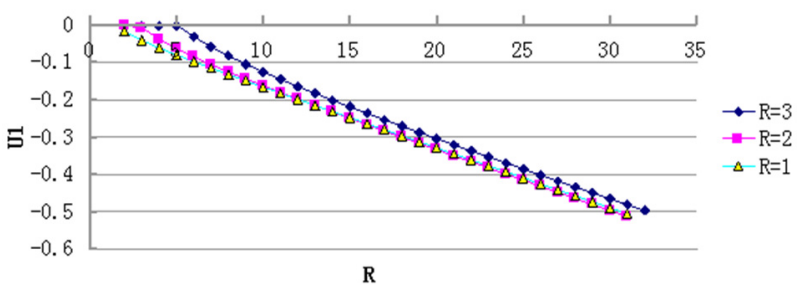

Figure 4. Comparison of U1 under different curvature

From $\mathrm{R}=3 \mathrm{~m}$ to $\mathrm{R}=1 \mathrm{~m}$, it can be found that the initial amount of stress, strain and displacement increases gradually in the structure. When $r=3 \mathrm{M}$, the minimum stress in the structure is zero, that is, it is not affected by the pressure from the soil, and the changes of strain and displacement also conform to this conclusion; When $\mathrm{R}=$ $1 \mathrm{~m}$, the initial stress in the structure can exceed 6Mpa, and the initial strain can reach 0.04 , which is very large. The variation of $R=2 \mathrm{~m}$ between $\mathrm{R}=3 \mathrm{M}$ and $\mathrm{R}=1 \mathrm{~m}$ is between the two curvatures.

Taking a general view of the stress variation law along the radial direction in each model, the distribution and size of stress in the structure and its distribution and size in the soil are very different, so the stress change rate at the interface often has a sudden change, which is related to the mechanical properties of the interface, But at the same time, we should also see the important role of soil arching effect.

When the material can yield, it will yield first along the radial direction at the outside of the structure, and produce strain to the inside, which leads to the contact gap between the soil and the structure in contact with the structure becoming larger, so the soil will bear the pressure of another layer of soil close to it according to its own arch. It can be predicted that when the $n+1$ soil layer bears the pressure from the $n+1$ soil layer, the acting force and reaction force will not exist on the two contact surfaces, because they are not "close" contact in the traditional sense. The certain self-bearing capacity of the $\mathrm{n}+1$ soil layer leads to the earth pressure transmitted to the $\mathrm{n}+1$ soil layer being less than the force originally transmitted to the $n+1$ soil layer, In this way, the boundary which is divided into many concentric circles will be generated in the contour map, but it is not possible in practice. The premise of soil arching effect is that one of the contact parts will yield or have a large displacement, which will lead to the change of the original contact and the redistribution of stress.

In this model, the prediction of soil arch effect is the same as the actual location, which is located near the soil surface. Because of the huge difference between the elastic modulus of soil and structure, the large deformation of the soil near the soil will cause a certain 
range of soil mass to form a closed circle and bear the surrounding soil pressure. The degree of exertion of soil arch effect can be theoretically expressed by the degree of stress change in soil before and after the effect occurs

$$
\frac{\Delta S_{11}}{\Delta R}
$$

The following tables show the changes of the earth pressure before and after the soil arching effect under different curvature of various materials.

Table2. Stress changes of $R=3 \mathrm{~m}$ contact surface at $5 \mathrm{MPa}$ confining pressure level

\begin{tabular}{|c|c|c|c|c|c|}
\hline$r(\mathrm{~m})$ & elastic & plastic & $\begin{array}{c}\text { linear } \\
\text { strain- } \\
\text { hardening }\end{array}$ & $\begin{array}{c}\text { logarithmic } \\
\text { strain } \\
\text { power } \\
\text { hardening }\end{array}$ & rigid \\
\hline 1.95 & $-6.77 \mathrm{e} 6$ & $-6.75 \mathrm{e} 6$ & $-6.65 \mathrm{e} 6$ & $-6.76 \mathrm{e} 6$ & $-6.42 \mathrm{e} 6$ \\
\hline 2.60 & $-6.37 \mathrm{e} 6$ & $-6.35 \mathrm{e} 6$ & $-6.35 \mathrm{e} 6$ & $-6.36 \mathrm{e} 6$ & $-6.08 \mathrm{e} 6$ \\
\hline 3.25 & $-6.04 \mathrm{e} 6$ & $-6.02 \mathrm{e} 6$ & $-6.02 \mathrm{e} 6$ & $-6.03 \mathrm{e} 6$ & $-5.85 \mathrm{e} 6$ \\
\hline
\end{tabular}

Table3. Stress changes of $R=2 \mathrm{~m}$ contact surface at $5 \mathrm{MPa}$ confining pressure level

\begin{tabular}{|c|c|c|c|c|c|}
\hline$r(\mathrm{~m})$ & elastic & plastic & $\begin{array}{c}\text { linear } \\
\text { strain- } \\
\text { hardening }\end{array}$ & $\begin{array}{c}\text { logarithmic } \\
\text { strain } \\
\text { power } \\
\text { hardening }\end{array}$ & rigid \\
\hline 0.68 & $-6.70 \mathrm{E} 6$ & $-6.39 \mathrm{E} 6$ & $-6.39 \mathrm{E} 6$ & $-6.70 \mathrm{E} 6$ & $-6.42 \mathrm{E} 6$ \\
\hline 1.37 & $-6.08 \mathrm{E} 6$ & $-5.94 \mathrm{E} 6$ & $-5.94 \mathrm{E} 6$ & $-6.08 \mathrm{E} 6$ & $-6.08 \mathrm{E} 6$ \\
\hline 2.05 & $-5.75 \mathrm{E} 6$ & $-5.68 \mathrm{E} 6$ & $-5.68 \mathrm{E} 6$ & $-5.75 \mathrm{E} 6$ & $-5.85 \mathrm{E} 6$ \\
\hline
\end{tabular}

Table4. Stress changes of $R=1 \mathrm{~m}$ contact surface at $5 \mathrm{MPa}$ confining pressure level

\begin{tabular}{|c|c|c|c|c|c|}
\hline$r(\mathrm{~m})$ & elastic & plastic & $\begin{array}{c}\text { linear } \\
\text { strain- } \\
\text { hardening }\end{array}$ & $\begin{array}{c}\text { logarithmic } \\
\text { strain } \\
\text { power } \\
\text { hardening }\end{array}$ & rigid \\
\hline 0.00 & $-6.17 \mathrm{E} 6$ & $-6.17 \mathrm{E} 6$ & $-6.17 \mathrm{E} 6$ & $-6.17 \mathrm{E} 6$ & $-6.42 \mathrm{E} 6$ \\
\hline 0.68 & $-5.60 \mathrm{E} 6$ & $-5.60 \mathrm{E} 6$ & $-5.60 \mathrm{E} 6$ & $-5.60 \mathrm{E} 6$ & $-6.08 \mathrm{E} 6$ \\
\hline 1.37 & $-5.37 \mathrm{E} 6$ & $-5.37 \mathrm{E} 6$ & $-5.37 \mathrm{E} 6$ & $-5.37 \mathrm{E} 6$ & $-5.85 \mathrm{E} 6$ \\
\hline
\end{tabular}

In each curvature radius, with the increase of radius, the change rate of stress relative to radius is gradually reduced, which shows that there is soil arching effect around the yielding soil at the interface, but in order to compare the degree of soil arching effect under different curvature conditions, it is necessary to conduct in-depth and detailed analysis on the change law of stress along the radial direction under each curvature.

\section{Conclusions}

A general model is established by FEM. In the analysis of the influence of curvature change factors on the results, we can see that:

1) For the models with different curvature conditions, the scaled model changes not only the curvature, but also the thickness of the structure, so the stiffness will also decrease. Some models with material mode will not converge due to too small stiffness. Therefore, the first problem that should be paid attention to after increasing the curvature is to reduce the external stress level of the model. In addition, under the condition of finite curvature, there will be obvious soil arching effect. On the one hand, at a higher stress level, the yield of soil near the contact surface is very obvious, and the adjacent outer soil layer can bear more stress, and the change rate of stress along the radial direction will be very obvious; On the other hand, the structure itself is an arched structure, and the constraint of boundary conditions makes it easier to form layered support arch between the soil, which can play the role of soil arch.

2) For the model with the same material and different curvature, the larger the stress level is, the smaller the stress attenuation is, the greater the stress transferred to the structure will be, and the more unfavorable the bearing capacity of the structure will be; On the contrary, if the stress level is small, the stress attenuation will be great, and even the stress transferred to the structure will be reduced to zero, which will be beneficial to the bearing capacity of the structure.

\section{References}

1. Y.R. Ren, Y.B. Liu, X.Y. Gu, Mechanics in engineering 26, 6 (2004)

2. W.P. Li, Chinese journal of geotechnical engineering 22, 4 (2000)

3. Y.R. Ren, Y.B. Liu, China offshore platform 21, 3 (2006)

4. Y.R. Ren, Y.B. Liu, X.Y. Gu, China offshore platform $16(2001)$

5. R. F. Goodman, R. L. Taylor, Journal of Soil Mechanics and Foundation Engineering Division, 94 (1968)

6. J. Wang, G.L. Li, X.Q. Li, G. Hu, GongluJiaoTongKeJi, 13, 2 (2017)

7. T. H. Lu, F. B. Bao, Journal of hydraulic engineering 2 (2000)

8. K. Terzaghi, Theoretical soil mechanics, Jhon Wiley and Sons, (1943) 